Fecha de recepción: abril 2008 Fecha de aceptación: mayo 2008 Versión final: diciembre 2008

\section{La comunicación con el gobierno}

Hernán Maurette ${ }^{(*)}$

${ }^{(*)}$ Politólogo graduado en la Universidad Católica Argentina, periodista de oficio y se dedica a las Re-
laciones Públicas. Preside la Comisión Corporativa del Consejo Profesional de Relaciones Públicas.

Resumen: La gestión de la comunicación con el Gobierno, o Asuntos Públicos, es un área específica de la comunicación corporativa y, al igual que el resto de las prácticas comunicacionales, presenta sus propias características e implicancias. El cuadro se compone con las particularidades del emisor -que puede ser una empresa, una ONG u otro tipo de institución-, más el receptor que es el público gobierno en general, si bien también existen segmentos específicos del público gubernamental a los que se dirige la acción comunicacional. Así, de este entretejido de variables surge el diseño del Plan de Comunicación que se inscribe en el área de gestión de las Relaciones Públicas conocida como Relaciones con el Gobierno, cuyos desafíos se plantean en el presente trabajo.

Palabras claves: Asuntos Públicos - Comunicación con el Gobierno - comunicación empresaria - comunicación institucional - gestión comunicacional - grassroot lobbying - Imagen - Lobbista - Lobbying - ONGs - Organización - planes de comunicación - Relaciones Gubernamentales - Relaciones Públicas.

[Resúmenes en inglés y portugués en las páginas 134-135]

\title{
Introducción
}

Las relaciones gubernamentales constituyen una de las áreas de gestión de la comunicación corporativa, y por lo tanto, de posible especialización para el profesional de Relaciones Públicas. Es una actividad que adquiere mayor relevancia en aquellas empresas insertas en determinados sectores, que se caracterizan por tener un alto nivel de regulación gubernamental, como por ejemplo las empresas de servicios públicos.

En estas organizaciones, es común que el área de relaciones gubernamentales tenga un departamento independiente o, un área específica dentro del departamento de comunicaciones (entendiendo que las características de la organización es la que determina las características de la estructura comunicacional). Esto se debe a que las decisiones de los organismos públicos, locales, nacionales y regionales, son las que inciden directamente en la operación de la empresa. Así, los relacionistas públicos que elijan realizar su carrera profesional en esta área de gestión de la comunicación, se convertirán a través de la práctica en especialistas en asuntos públicos.

Entre sus funciones, por un lado se encuentran las dedicadas a recopilar y analizar información, y realizar un seguimiento de las actividades de organismos legislativos. Para esto, desde hace años se cuenta con servicios específicos de 'monitoreo parlamentario' -que se contrata al igual que la agen- 
cia de clipping para el monitoreo de la prensa-y su objetivo es mantenerse al día de los temas que van surgiendo para el debate y el posible sometimiento a votación.

Por otro lado, en la función del especialista en asuntos públicos se encuentra la de divulgar el punto de vista de la dirección de la empresa al público gobierno, difundir información sobre la posición de una empresa a una gran variedad de públicos claves, y la de colaborar con el Gobierno en proyectos de beneficio mutuo.

Se hace necesario entonces, aclarar muy puntualmente, algunos términos que están estrechamente ligados con los asuntos públicos y las relaciones gubernamentales, y muchas veces sus limitaciones son difusas.

Uno de ellos es el lobbying, cuyo ejercicio es realizado por un lobbista que es:

La persona que procura influir en las votaciones legislativas o en las decisiones gubernamentales. En otras palabras, el lobbista dirige todas las energías a encargada de obstaculizar, enmendar o aprobar las propuestas legislativas y las normas del poder ejecutivo... Los lobbistas operan ante gobiernos locales, nacionales y regionales. (Wilcox D., et. al, 2008, p.609).

El otro término de surgimiento en los últimos años es el de Grassroot Lobby, que es una acción que está dirigida a la movilización de las bases, es decir, a los sectores más masivos de la sociedad desde donde se espera haya un efecto hacia las esferas gubernamentales para impactar en estas decisiones. Esta práctica ya involucra la inversión de millones de dólares en Europa y Estados Unidos, y resulta atractiva especialmente para los grupos de presión ya que aún carece de normativa que la regule. Las herramientas más comunes que usa el Grassroot Lobby son la publicidad de defensa (advocacy advertising), las líneas telefónicas gratuitas, las Webs, los emailings y las cartas del público dirigidas al Congreso y a representaciones gubernamentales. En Argentina, se han venido viendo cada vez más seguido ejemplos de esta práctica, especialmente en los dos últimos años.

Habiendo realizado una contextualización de las implicancias generales de la gestión de la Comunicación con el Gobierno, se realizará a continuación un abordaje de las particularidades más sobresalientes.

\section{La Comunicación con el Gobierno}

La gestión de la comunicación con el Gobierno tiene muchas implicancias. No es lo mismo establecer un Plan de Comunicación corporativa, que cuando la organización que emite el mensaje tiene interés en ser escuchada por el Gobierno, o que sea, que el Gobierno esté atento en lo que la institución tiene por decir.

Por otra parte, el emisor puede ser una empresa, una organización no gubernamental (ONG), una institución sanitaria o escolar entre otras; y el receptor no necesariamente tiene que ser el titular del Poder Ejecutivo, sino que se inaugura una diversidad de segmentos posibles a los que comunicar que conforman el público gubernamental. Puede ser un ministro, un secretario, un funcionario o un organismo; el Congreso o una de sus comisiones, o gobiernos provinciales o municipales, en cualquiera de esos niveles mencionados; hasta incluso una embajada en particular.

Cada una de estas instancias requiere de distintos medios y por lo tanto, tiene sus propias sensibilidades, necesidades e intereses. 


\section{Las finalidades}

Siempre hay que estar muy atento a las finalidades, a los objetivos corporativos que se persiguen. Hay que saber distinguir si lo que se quiere es informar, sondear, sensibilizar o persuadir. De esta definición se derivará el medio necesario para hacerlo.

Por ejemplo, si el objetivo es informar habrá que ver si esa necesidad es periódica y en qué medida, o si es puntual.

De ser habitual, por ejemplo, habrá que establecer una sistematización en los envíos de información de modo que permita formalizar un vínculo -una forma de relacionarse con ese público específico-, de una manera tal que evite sensibilizar o persuadir. La presentación de la información se hará siempre de una misma forma y deberá ajustarse al procedimiento, y esto será lo que permita lograr previsibilidad y, consecuentemente, confianza.

En el caso de que se perciba que un dato allí presentado pueda llegar a despertar una reacción, aún cuando sea positiva, habrá que medir la necesidad que pueda haber de actuar de alguna manera de modo tal de favorecer una sensibilización o una persuasión en algún sentido. En otras palabras: aún si el emisor quisiese que el dato pase desapercibido, puede que el caso requiera una llamada extraordinaria para aclarar alguna situación que deriva en una variación significativa de una tendencia.

Otro sería el caso cuando el emisor necesite llamar la atención del receptor, de modo tal de persuadirlo o, simplemente, de sensibilizarlo con algún efecto. En esta situación se podría convocar a una reunión para llamar la atención para advertir la carencia de movimientos de alguna variable, por ejemplo, e insinuar acerca de los perjuicios que esto pueda significar o, por el contrario, destacar el mérito y los costos que ha implicado esa continuidad.

Si bien es complejo teorizar en abstracto, también es muy fácil para el lector entender la necesidad que surge a la hora de encarar una campaña de comunicación que tenga el objeto de sensibilizar o de persuadir acerca de un punto que es y que será naturalmente desconocido por el receptor, excepto que alguien quiera darlo a conocer.

\section{Los medios}

Este tipo de práctica de la comunicación, al igual que el resto, implica la necesidad de elegir un vehículo determinado para evitar la contaminación del mensaje. Es más, se buscará un medio que potencie algún atributo más que otro según surge de los objetivos definidos en el plan.

En estos casos, es evidente que se deberán evaluar todas las posibilidades para seleccionar la que ofrezca las condiciones más óptimas para el logro de la finalidad que se persigue.

¿Hace falta sensibilizar? Una campaña pública que tome al receptor como un ciudadano común puede resultar muy adecuada; más aún, el receptor podría recibir mejor un mensaje que no espera y que no lo toma como un decisor oficial, sino que le llega a su casa o a su entorno íntimo, sin presión alguna. Por el contrario, las ONG's acuden más habitualmente a medios más directos como una marcha frente a una sede, por ejemplo con acciones de panfleteadas. Muchas veces, tienen que ver con cuestiones de escasez de recursos o, tal vez, a que buscar impedir o forzar algo.

En tal caso, se apela a la persuasión. Una picardía: ¿qué tal si la referida marcha o panfleteada no fuera propiamente organizada por una ONG carente de recursos, sino de alguna otra organización que busca por este medio lo que la legitimidad no le permite procurar de otra manera?

\section{El mensaje}

Siempre es lo mismo y aplican las mismas normas que rigen para las otras tipologías de gestión 
comunicacional. El mensaje debe ser claro, sencillo y directo. La estrategia de una campaña puede ser más sofisticada y buscar un resultado que se obtenga mediante la suma de sensaciones lograda mediante distintos estímulos.

La información es algo muy concreto, pero la sensibilización requiere lenguajes y formatos determinados.

La persuasión puede requerir de la modalidad presencial: una reunión, una presentación, un breve encuentro, buscado o no. Todas estas modalidades exigen habilidades diferentes: un discurso o una presentación que implican el dominio de la oratoria; un texto en cuyo caso la redacción es fundamental; una película, un spot, o una presentación en power point, de una facilidad plástica y audiovisual; o la internet con las innumerables funcionalidades de interacción que ofrece.

\section{Los tiempos y los ámbitos}

De la misma forma en que se dice que el mensaje debe estar ajustado a sus objetivos, es que se entiende que la periodicidad y la oportunidad pueden modificar enormemente el objetivo procurado.

La definición de la duración que debe tener un mensaje es en relación al logro del equilibrio justo para que no deje nada afuera, ni sobreabunde ni aburra, siendo éste un aspecto clave.

La definición de los ámbitos a los que se quiere impactar, sensibilizar o persuadir, será gravitante. Es muy importante tener presente que no se puede convencer a todos de todo, y acá se pone en juego la habilidad profesional del comunicador a la hora de proponer las mejores opciones para cada situación. Tal vez se pueda sensibilizar a muchos de algo, pero movilizar a alguien para algo específico -como tomar una determinación política- difícilmente se pueda realizar de manera masiva.

\section{Conclusión}

La república exige que los actos de gobierno sean públicos y la democracia exige transparencia y ejemplaridad. La comunicación de las cuestiones que son públicas es clave en este sentido. Cuando se procura una determinación que puede implicar una política pública, a los comunicadores privados se les aplican las mismas responsabilidades que a los que se deben a la administración de la cosa pública.

\section{Referencias bibliográficas}

Wilcox, D, Cameron G. y Cifra J. (2001). Relaciones Públicas, estrategias y tácticas. $7^{\circ}$ edición. Madrid: Addison-Wesley, Pearson Education.

\footnotetext{
Summary: The management of the communication with the Government, or Public Affairs, is a specific area of the corporate communication and, like the rest of the communicational practices, presents its particular characteristics. The picture is made up with the singularities of the sender - that can be a company, a Non Governmental Organization or another type of institution- and the receiver that normally is the "audience government" although the communicational action goes also to other specific segments of the governmental public. Thus, from this complex net of variables arises the design of the communication plan that registers in the area of management of public relations well-known like Relations with the Government, whose challenges are considered in the present work.
}

Key words: communication plans - communicational management - corporate communication - Government Communica- 
tions - Governmental Relations - grass root lobbying - Image - Lobbying - Lobbyist - Non Governmental Organizations - Organization - Public Affairs - Public Relations.

Resumo: A gestão da comunicação com o governo, o assuntos públicos, é uma área especifica da comunicação corporativa e, ao igual que o resto das práticas das comunicações, apresenta seu pró pias características e implicâncias. O quadro compõe - se com as particularidades de emissor que pode ser uma empresa, uma ONG ou outro tipo de instituição, alem do receptor que é o público governo em geral, se bem também existem segmentos específicos do publico governamental aos que se dirige a ação comunicacional. Assim surge a desenho do plano de comunicação que inscreve - se na área de gestão das relações publicas conhecida como relações com governo, cuyos desafios plamteam - se no presente trabalho.

Palavras chave: Assuntos Públicos - Comunicação com o governo - Gestão Comunicacional - grassroot lobbying - Imagem - lobbista - ONG’s lobbying - Organização - Planos de Comunicação - Relações governamentales - Relações Públicas. 